Marek Saj

Cardinal Stefan Wyszynski University in Warsaw, Poland

\title{
Las facultades para la confesión en el Código de Juan Pablo II
}

\section{Authorization to Hear Confessions in the Code of Pope John Paul II}

\section{Abstract}

According to the law of the Church, contained mainly in the Code of Canon Law, priests are entitled to certain rights and obligations arising from their Holy Orders. Some of them require also appropriate faculties in addition to the orders. This is the case in relation to the sacrament of penance and reconciliation. This so-called faculty is required in order to exercise this sacrament validly. The of such faculty causes the incurrence of ecclesiastical penalty of suspension latae sententiae. This text examines the norms of the Codex regarding the conferment of the faculty to administer the sacrament of penance, its use and the ecclesiastical penalties incurred for hearing confessions without such faculties.

\section{Keywords}

Confession, authorization, ecclesiastical punishment.

\section{Introducción}

Para la celebración válida del sacramento de la penitencia, es suficiente la potestad del orden sacerdotal? A tal pregunta, la respuesta puede ser solamente una: no! Para la validez del sacramento de la reconciliación de los penitentes con Dios, junto con el orden sacerdotal, es necesario que el sacerdote tenga la autorización, que el Código del Derecho Canónico denomina la facultad 
( facultas $)^{1}$, y que antes se llamaba jurisdicción (iurisdictio) ${ }^{2}$. Además, el legislador recuerda a todos sacerdotes que el confesor, como ministro de la Iglesia en la celebración del sacramento de la penitencia, debe seguir fielmente las enseñanzas del Magisterio y las normas promulgadas por la autoridad competente ${ }^{3}$. Si un presbítero confiesa sin la debida autorización, excepto en los casos de los cuales habla el Código de Derecho Canónico, este sacramento lo celebra inválidamente. Esta situación nunca debería suceder, porque se daría una evidente contradicción: por una parte el confesor liberaría al penitente del pecado y, a la vez, él incurriría en el pecado ${ }^{4}$. No se trata de un problema moral sin relevancia. Por confesar sin facultad, el sacerdote incurre en suspensión latae sententiae y, además, puede ser castigado con otras penas, de acuerdo a la gravedad de su culpa, sin excluir la excomunión.

Confesar sin facultad conlleva graves consecuencias. Hoy no faltan casos en los que se da „un trato ligero” a esta exigencia eclesiástica, incluso despreciándola. Por eso, es oportuno recordar las condiciones que pone la Iglesia para la válida reconciliación de los penitentes con Dios en el sacramento de la penitencia y la normatividad canónica vigente al respecto.

\section{Las razones que exigen que el confesor tenga facultades para el sacramento de la reconciliación}

Podemos preguntar: por qué la Iglesia exige para su validez, las facultades para celebrar el sacramento de la penitencia? Por qué no es suficiente que el ministro tenga la potestad del orden sacerdotal, como en la celebración de la Eucaristía, para la cual no es necesario tener facultades adicionales? Uno de los argumentos a favor de la facultad es la participación en el poder y ministerio del obispo diocesano, el cual vela y supervisa la celebración del sacramento de la

${ }^{1}$ Código de Derecho Canónico del año 1983 (en adelante: CDC), can. 966 § 1: „Para absolver válidamente de los pecados se requiere que el ministro, además de la potestad de orden, tenga facultad de ejercerla sobre los fieles a quienes da la absolución".

${ }^{2}$ Código de Derecho Canónico del año 1917, can. 872: „Praeter potestatem ordinis, ad validam peccatorum absolutionem requiritur in ministro potestas iurisdictionis, sive ordinaria sive delegata, in poenitentem"; Cfr. L. Adamowicz, Zakres uprawnień spowiednika wedtug prawa powszechnego Kościoła łacińskiego i prawa wspólnego katolickich Kościołów wschodnich, Lublin 2001, p. 94.

${ }^{3}$ Cfr. CDC, can. $978 \S 2$.

${ }^{4}$ Cfr. M. Pastuszko, Sakrament pokuty i pojednania, Kielce 1999, p. 197. 
penitencia según las normas del derecho en su diócesis 5 . Con la consagración, por medio del orden sagrado, el sacerdote recibe la potestad para celebrar el sacramento de la reconciliación, pero para su ejercicio necesita además la autorización - las facultades canónicas, es decir, el permiso legal otorgado por la autoridad competente, en virtud de la comunión interior de la Iglesia con su Cabeza y con sus miembros ${ }^{6}$.

La facultad que debe tener el confesor es un elemento necesario para actuar en sintonía con la obra de la Iglesia (Cristo y su Cuerpo) y permanecer en la comunidad eclesiástica. Una de las manifestaciones visibles de la comunión eclesial es el oficio o la facultad que la Iglesia otorga ${ }^{7}$.

Otro argumento a favor de la necesidad de facultad para la confesión es la aptitud e idoneidad del presbítero exigidas por el legislador eclesiástico ${ }^{8}$. La facultad de oír confesiones sólo se concede a los presbíteros que hayan sido considerados aptos mediante un examen, o cuya idoneidad conste de otro modo. Para esta finalidad sirve, por ejemplo, el examen de jurisdicción, y otros exámenes que suelen exigirse durante los primeros cinco o más años después de la ordenación sacerdotal. Además, si existiera alguna duda acerca de la aptitud o idoneidad del confesor, siempre se debe comprobar e incluso revocar las facultades para celebrar el sacramento de la penitencia. Si la autorización para confesar derivara solamente del orden sacerdotal, la autoridad eclesiástica no podría prohibir el ejercicio de esta función bajo la sanción de invalidez. Entonces, el presbítero al que se le ha prohibido celebrar el sacramento de la reconciliación, confesaría ilícita pero válidamente. Encontramos ciertos presbíteros, que por el bien de los fieles, y a veces del suyo propio, no deben ser confesores. Este problema se soluciona por medio de la revocación o la no prolongación de la facultad para celebrar el sacramento de la penitencia y la reconciliación?.

${ }^{5}$ CDC, can. $835 \S 1$ : „Ejercen en primer término la función de santificar los Obispos, que al tener la plenitud del sacerdocio, son los primeros dispensadores de los misterios de Dios y, en la Iglesia a ellos encomendada, los moderadores, promotores y custodios de toda la vida litúrgica". $\S 2$ : „También la ejercen los presbíteros, quienes participando del sacerdocio de Cristo, como ministros suyos, se consagran a la celebración del culto divino y a la santificación del pueblo bajo la autoridad del Obispo".

${ }^{6}$ Cfr. M. Górka, La natura de potestas absolvendi a peccatis, Roma 1992, p. 36.

${ }^{7}$ Cfr. M. Żurowski, Problem władzy i powierzania urzędów w Kościele katolickim, Kraków 1985, p. 76, 166-167.

${ }^{8}$ CDC, can. 970: „La facultad de oír confesiones sólo debe concederse a los presbíteros que hayan sido considerados aptos mediante un examen, o cuya idoneidad conste por otro modo"; Cfr. ibidem, can. 1052; J.S. Płatek, Sprawowanie sakramentu pokuty i pojednania, Częstochowa 2001, p. 333-349.

\footnotetext{
${ }^{9}$ Cfr. M. Pastuszko, Sakrament pokuty i pojednania, cit., p. 235-238.
} 


\section{Las facultades ipso iure}

Para la validez de la celebración del sacramento de la penitencia y reconciliación se exige que el sacerdote tenga las facultades. Se las puede obtener de diferente manera. Las facultades ipso iure en la Iglesia Católica las reciben el Obispo de Roma - posee esta autorización de confesar a los fieles en todas partes, es decir, en toda la Iglesia. Los cardenales - pueden válidamente confesar en todas partes sin pedir permiso al ordinario del lugar. Los obispos tienen ipso iure la facultad para confesar lícitamente en toda Iglesia. Sin embargo, por respeto a la autoridad concedida al obispo diocesano, los obispos pueden confesar lícitamente en cualquier sitio, a no ser que el obispo diocesano se oponga en un caso concreto ${ }^{10}$.

\section{Las facultades por razón del oficio}

En virtud del oficio reciben las facultades para confesar: el ordinario del lugar - el obispo diocesano y todos los que se le equiparan por el derecho ${ }^{11}$; el canónigo penitenciario ${ }^{12}$; el párroco, es decir, cada presbítero que obtuvo el oficio de administrar la parroquia, incluso el párroco personal $1^{13}$; y los que se equiparan con el párroco por el derecho, es decir, el administrador de la parroquia, el

${ }^{10}$ CDC, can. $967 \S 1$ : „Además del Romano Pontífice, los Cardenales tienen ipso iure la facultad de oír confesiones de los fieles en todo el mundo; y asimismo los Obispos, que la ejercitan también lícitamente en cualquier sitio, a no ser que el Obispo diocesano se oponga en un caso concreto"; Cfr. M. Pastuszko, Sakrament pokuty i pojednania, cit., p. 200-201.

${ }^{11}$ CDC, can. 968 § 1, can. 134 § 1: „Por el nombre de Ordinario se entienden en derecho, además del Romano Pontífice, los Obispos diocesanos y todos aquellos que, aun interinamente, han sido nombrados para regir una Iglesia particular o una comunidad a ella equiparada según el can. 368, y también quienes en ellas tienen potestad ejecutiva ordinaria, es decir, los Vicarios generales y episcopales; así también, respecto a sus miembros, los Superiores mayores de institutos religiosos clericales de derecho pontificio y de sociedades clericales de vida apostólica de derecho pontificio, que tienen, al menos, potestad ejecutiva ordinaria”. § 2: „Por el nombre de Ordinario del lugar se entienden todos los que se enumeran en el $\S 1$, excepto los Superiores de institutos religiosos y de sociedades de vida apostólica. Can. 368: „Iglesias particulares, en las cuales y desde las cuales existe la Iglesia católica una y única, son principalmente las diócesis a las que, si no se establece otra cosa, se asimilan la prelatura territorial y la abadía territorial, el vicariato apostólico y la prefectura apostólica así como la administración apostólica erigida de manera estable".

${ }^{12} \mathrm{Cfr}$. CDC, can. 968 § 1; can. 508 § 1: „El canónigo penitenciario, tanto de la iglesia catedral como de una colegiata, tiene, en virtud del oficio, la facultad ordinaria, no delegable, de absolver en el fuero sacramental de las censuras latae sententiae no declaradas, ni reservadas a la Santa Sede, incluso respecto de quienes se encuentren en la diócesis sin pertenecer a ella y respecto a los diocesanos, aun fuera del territorio de la misma".

${ }^{13}$ Cfr. CDC, can. $968 \S 1$. 
capellán - para los fieles encomendados a su atención pastoral ${ }^{14}$, el rector del seminario - para los habitantes encomendados a su atención ${ }^{15}$.

Los párrocos reciben las facultades en el momento de recibir su cargo, es decir, las tienen en virtud de su oficio. No tienen que pedirlas al ordinario de lugar. Sin embargo, se dan casos en los que a los párrocos se les concede las facultades por medio de un decreto administrativo del ordinario, de la misma manera que se las concede a otros que no las tienen ipso iure o por oficio. Pero tales concesiones indican el desconocimiento del orden canónico vigente.

Otras personas que reciben la facultad de confesar en virtud del oficio, son los superiores de los institutos clericales de vida consagrada de derecho pontificio y de las sociedades de vida apostólica de derecho pontificio, con tal que tengan, de acuerdo con las propias constituciones, un poder de gobierno ${ }^{16}$. Sin embargo, los superiores pueden confesar a sus propios súbditos solamente cuando ellos se lo pidan espontáneamente ${ }^{17}$.

\section{La concesión de facultades para administrar el sacramento de la penitencia}

Si el sacerdote no tiene un oficio que le concede las facultades para la confesión sacramental, puede recibirlas por concesión del ordinario de lugar (es el caso de los sacerdotes miembros de los institutos de vida consagrada y de las sociedades de vida apostólica a los que el superior da facultades para confesar a sus súbditos).

Los ordinarios de lugar otorgan las facultades a los presbíteros tanto diocesanos como religiosos. Para conceder la facultad de confesar, no es necesario que el presbítero tenga un oficio, la incardinación, o el domicilio permanente o temporal en la jurisdicción del mismo. El ordinario de lugar puede conceder las facultades

${ }^{14}$ Cfr. CDC, can. $566 \S 1$.

${ }^{15}$ Cfr. CDC, can. 268, 985.

${ }^{16}$ CDC, can. 968 § 2: „En virtud del oficio, tienen la facultad de oír confesiones de sus súbditos o de aquellos que moran día y noche en la casa, aquellos Superiores de un instituto religioso o de una sociedad de vida apostólica clericales de derecho pontificio que, según las constituciones, están dotados de potestad ejecutiva de régimen, permaneciendo lo establecido en el can. 630, $\S 4$ "; Cfr. J. Krukowski, Sakrament pokuty, en: Komentarz do Kodeksu Prawa Kanonicznego, t. III/2, ks. IV: Uświęcające zadanie Kościoła, J. Krukowski (dir.), Pallottinum 2011, p. 153.

${ }^{17} \mathrm{CDC}$, can. 630 § 4: „Los Superiores no deben oír las confesiones de sus súbditos, a no ser que éstos lo pidan espontáneamente"; Cfr. ibidem, can. 985; E. Gambari, Życie zakonne po Soborze Watykańskim II, Kraków 1998, p. 451, 598, 659. 
a todo sacerdote idóneo, aunque sea por motivos de amistad. Actualmente se puede tener la autorización de confesar por parte de varios ordinarios. Pero, teniendo las facultades del ordinario de lugar del domicilio permanente (el domicilio temporal aquí no es suficiente), se poseen las facultades de confesar en cualquier Iglesia, a no ser que se trate de un sacerdote al cual el obispo ha prohibido en un caso concreto ejercer estas facultades en su diócesis ${ }^{18}$.

Las facultades más importantes son las concedidas por el ordinario de lugar donde el sacerdote tiene domicilio permanente. No se trata del domicilio anotado en la Cédula de Identidad. Así que, trasladándose a una nueva diócesis, lo que sucede frecuentemente con los presbíteros de los institutos religiosos o sociedades de vida apostólica, deben pedir las facultades al ordinario de lugar. Los sacerdotes diocesanos, que generalmente atienden los asuntos pastorales en el territorio de su propia diócesis, no tienen problema con la pérdida de la facultad para confesar debida al abandono definitivo de la diócesis en la cual el ordinario se las ha concedido. El sacerdote perteneciente a un instituto de vida consagrada o a una sociedad de vida apostólica, no obtiene tal facultad por su propia cuenta. Es el superior provincial que la pide a los ordinarios del lugar para los miembros de su provincia; la curia diocesana envía el documento a la casa religiosa correspondiente o a la curia provincial que lo transmite al interesado o a su superior. Es importante que el sacerdote nunca confiese si no tiene certeza de que se le han otorgado las facultades. Hay que subrayar que, ni aún para casos excepcionales, ningún párroco puede conceder un permiso que faculte a un sacerdote a confesar, lo que desgraciadamente sucede de vez en cuando. Quien confiesa, sin obtener la facultad respectiva, celebra inválidamente el sacramento e incurre en penas canónicas.

${ }^{18}$ CDC, can. 967 § : „Quienes tienen facultad habitual de oír confesiones, tanto por razón del oficio como por concesión del Ordinario del lugar de incardinación o del lugar en que tienen su domicilio, pueden ejercer la misma facultad en cualquier parte, a no ser que el Ordinario de algún lugar se oponga en un caso concreto, quedando en pie lo que prescribe el can. 974 §§ 2 y 3 : Si la facultad de oír confesiones es revocada por el Ordinario del lugar que la concedió, del que trata el can. $967 \S 2$, el presbítero queda privado de la misma en todas partes; si es revocada por otro Ordinario del lugar, queda privado de ella sólo en el territorio del que la revoca”. § 3: „Todo Ordinario del lugar que revoca a un presbítero la facultad de oír confesiones debe comunicarlo al Ordinario propio del presbítero por razón de la incardinación o, si se trata de un miembro de un instituto religioso, a su Superior competente". 


\section{Las facultades para confesar que conceden los superiores de institutos de vida consagrada 0 de sociedades de vida apostólica}

Las facultades obtenidas del obispo diocesano que autorizan a los sacerdotes - miembros de institutos de vida consagrada y de sociedades de vida apostólica para reconciliar válidamente a los penitentes con Dios tienen sus limitaciones. Ellos pueden confesar a todos los penitentes, excepto a los miembros del propio instituto y a los que viven en las casas del instituto día y noche. La razón de esta norma está en que el ordinario de tales personas no es el obispo diocesano sino el ordinario propio, es decir, el provincial ${ }^{19}$. La potestad de conceder la facultad del confesor la tienen los superiores de los institutos clericales de vida consagrada y de las sociedades de vida apostólica por derecho pontificio, y este poder ejecutivo de gobernar se lo otorgan las constituciones del propio instituto. Trátese de sacerdote, religioso o diocesano, si no ha obtenido las facultades, confiesa inválidamente e incurre en la suspensión latae sententiae.

\section{Duración de las facultades para confesar}

La facultad para confesar se puede obtener por tiempo determinado o indeterminado ${ }^{20}$. Depende de las costumbres de cada diócesis. En algunas, la facultad se recibe mientras dure la permanencia en la misma. En tal caso, no hay necesidad de pedirlas cada año. Son válidas durante todo el tiempo que el sacerdote permanezca en la diócesis. Para los sacerdotes religiosos y miembros de las sociedades de vida apostólica, la facultad continúa vigente cuando se trasladan a otra casa en el territorio de la misma diócesis. Pero hay diócesis en las que hay que pedir anualmente la renovación de dichas facultades, porque el ordinario las concede por un tiempo determinado, por ejemplo para el año civil. Rara vez algún sacerdote ha recibido facultad para confesar solamente en un determinado lugar, por ejemplo, en una iglesia especial. En la práctica, son limitaciones temporales a las que están sujetos tales sacerdotes.

\footnotetext{
${ }^{19}$ Cfr. CDC, can. $969 \S 2$.

${ }^{20}$ Cfr. CDC, can. 972; M. Pastuszko, Sakrament pokuty i pojednania, cit., p. 239-240.
} 


\section{Manera de conceder la facultad habitual para confesar}

La facultad para confesar se concede generalmente por escrito. Las facultades habituales, es decir, definitivas, deben darse siempre por escrito, para que se las pueda verificar fácilmente ${ }^{21}$. Si sucediese que los superiores de un sacerdote idóneo pidieron por escrito al ordinario de lugar las facultades para confesar y ya pasó un tiempo prudente en el que ya debería llegar la respuesta escrita y hay necesidad de confesar, se puede suponer que las ha concedido y la suplencia de las facultades proviene de la institución „Ecclesia supplet”22. Se puede, sin embargo, servirse del mencionado derecho solamente en caso de necesidad; después hay que pedir la facultad y que la concesión de las mismas conste por escrito.

Puede suceder que el superior ha tardado en pedir al ordinario del lugar la facultad para un sacerdote que llegó a su comunidad y hay necesidad de confesar, porque por ejemplo es domingo. Entonces, se puede ubicar por teléfono al vicario episcopal (lo debe hacer el párroco o el superior de la comunidad, nunca el mismo interesado) y pedir oralmente las facultades que - como enseña la práctica siempre se las concede. Pero, enseguida hay que pedirlas por escrito. No se puede confesar permanentemente teniendo la facultad concedida sólo oralmente.

\section{La revocación de la facultad para confesar}

Las facultades para confesar no tienen carácter definitivo. Existe siempre la posibilidad de ser revocadas. La revocación consiste en la privación de las mismas y no solamente en la suspensión de las posibilidades de utilizarlas. El efecto de la suspensión está en la invalidez del sacramento celebrado y en las penas canónicas en las cuales incurre el sacerdote.

Puede revocar las facultades, por causa graves, solamente la autoridad que las concede ${ }^{23}$. La existencia de tal causa la verifica la autoridad que ha concedido las facultades. Esta causa tiene que ser grave, porque la revocación de la facultad puede afectar el buen nombre de la persona y todo hombre tiene derecho a su

\footnotetext{
${ }^{21}$ Cfr. CDC, can. 973; M. Pastuszko, Sakrament pokuty i pojednania, cit., p. 240-241.

${ }^{22}$ CDC, can. $144 \S 1$ : „En el error común de hecho o de derecho, así como en la duda positiva y probable de derecho o de hecho, la Iglesia suple la potestad ejecutiva de régimen, tanto para el fuero externo como para el interno”. § 2 : „La misma norma se aplica a la facultad de que se trata en los cann. 882, 883, 966 y $1111 \S 1 "$.

${ }^{23}$ Cfr. CDC, can. 974 § 1; J. Krukowski, Sakrament pokuty, cit., p. 158.
} 
buena reputación ${ }^{24}$. El ordinario del lugar puede revocar las facultades a cada uno de los sacerdotes a los que se las ha otorgado, tanto a sus propios presbíteros como a los religiosos. En este caso, se pierde la facultad de confesar en toda la Iglesia. Si lo revoca otro ordinario, el presbítero no puede confesar solamente en el territorio de su jurisdicción ${ }^{25}$. El ordinario que ha revocado la facultad para confesar debe informar al ordinario del lugar de la incardinación del presbítero, y en caso de ser un miembro de instituto de vida consagrada, a su superior competente $^{26}$. Si alguno se sintiera perjudicado por causa de la revocación de la facultad para confesar, siempre puede acudir a la autoridad competente por la vía administrativa prevista por el legislador eclesiástico ${ }^{27}$.

El mismo procedimiento se sigue con la revocación de la facultad concedida por el superior religioso a sus súbditos y a los que día y noche viven en sus casas, los cuales pierden la facultad de confesar a sus cohermanos. El presbítero pierde la facultad solamente para con los fieles, por el bien de los cuales la obtuvo ${ }^{28}$.

\section{Cese de la facultad para confesar}

La facultad para confesar en la toda Iglesia se puede perder: a consecuencia de la revocación directa de la facultad habitual; por pérdida del oficio, gracias al cual el sacerdote obtuvo esta facultad; por excardinación y pérdida de domicilio ${ }^{29}$.

Además, existen dos situaciones en las que el presbítero, aunque posea la facultad de confesar, no puede ejercerla válidamente. La primera concierne a una falsa denuncia del pecado de solicitación, cuando se prohíbe dar la absolución, hasta que el penitente no revoque formalmente la falsa denuncia y repare los daños ocasionados ${ }^{30}$. La segunda situación es la prohibición de absolver al cómplice del pecado contra el sexto mandamiento, bajo la sanción de invalidez del sacramento, excepto en peligro de muerte e incluso estando presente otro sacerdote ${ }^{31}$.

${ }^{24}$ CDC, can. 220: „A nadie le es lícito lesionar ilegítimamente la buena fama de que alguien goza ni violar el derecho de cada persona a proteger su propia intimidad".

${ }^{25}$ Cfr. CDC, can. 974 § 2; J. Krukowski, Sakrament pokuty, cit., p. 159.

${ }^{26}$ Cfr. CDC, can. 974 § 3; J. Krukowski, Sakrament pokuty, cit., p. 159.

${ }^{27}$ Ver: CDC, can. 1732-1739.

${ }^{28}$ Cfr. CDC, can. 974 § 4; J. Krukowski, Sakrament pokuty, cit., p. 159.

${ }^{29}$ Cfr. CDC, can. 967 § 2, can. 975.

${ }^{30}$ Cfr. CDC, can. 982; M. Pastuszko, Sakrament pokuty i pojednania, cit., p. 371-377.

${ }^{31}$ Cfr. CDC, can. 977; M. Pastuszko, Sakrament pokuty i pojednania, cit., p. 359-364. 
Existen otras situaciones que no permiten al confesor celebrar válida y convenientemente este sacramento. El derecho canónico en su parte penal y en relación con las penas de excomunión y entredicho, indica estas limitaciones que tienen como consecuencia prohibir la admisión a los sacramentos, es decir, la admisión a los sacramentos y la absolución ${ }^{32}$. La facultad del confesor queda restringida por las penas canónicas impuestas o declarada con una sentencia. La absolución de las mismas está reservada a la Santa Sede o al ordinario ${ }^{33}$. En cuanto a las penas en las que se incurre ipso facto, la facultad del confesor tiene límites cuando se trata de las excomuniones reservadas a la Santa Sede. Se trata de las siguientes delitos: violencia física contra el papa $^{34}$; profanación de las formas eucarísticas ${ }^{35}$; absolución, fuera del peligro de muerte, del cómplice en el pecado contra el sexto mandamiento ${ }^{36}$; violación directa del secreto de la confesión por el confesor ${ }^{37}$; la ordenación episcopal sin autorización de la Sede Apostólica $^{38}$.

${ }^{32} \mathrm{CDC}$, can. $1331 \S 1$ : „Se prohíbe al excomulgado: $1^{\circ}$. tener cualquier participación ministerial en la celebración del Sacrificio Eucarístico o en cualquier otra ceremonia de culto; $2^{\circ}$. celebrar los sacramentos o sacramentales, y recibir los sacramentos; $3^{\circ}$. desempeñar oficios, ministerios o cargos eclesiásticos, o realizar actos de régimen".

${ }^{33}$ Cfr. CDC, can. $1355 \S 1$.

${ }^{34}$ CDC, can. 1370 § 1: „Quien atenta físicamente contra el Romano Pontífice, incurre en excomunión latae sententiae reservada a la Sede Apostólica; si se trata de un clérigo, puede añadirse otra pena, atendiendo a la gravedad del delito, sin excluir la expulsión del estado clerical".

${ }^{35}$ CDC, can. 1367: „Quien arroja por tierra las especies consagradas, o las lleva o retiene con una finalidad sacrílega, incurre en excomunión latae sententiae reservada a la Sede Apostólica; el clérigo puede ser castigado además con otra pena, sin excluir la expulsión del estado clerical".

${ }^{36} \mathrm{CDC}$, can. $1378 \S 1$ : „El sacerdote que obra contra lo prescrito en el can. 977, incurre en excomunión latae sententiae reservada a la Sede Apostólica”. Can. 977: „Fuera de peligro de muerte, es inválida la absolución del cómplice en un pecado contra el sexto mandamiento del Decálogo".

${ }^{37} \mathrm{CDC}$, can. $1388 \S 1$, „El confesor que viola directamente el sigilo sacramental, incurre en excomunión latae sententiae reservada a la Sede Apostólica; quien lo viola sólo indirectamente, ha de ser castigado en proporción con la gravedad del delito".

${ }^{38}$ CDC, can.1382: „El Obispo que confiere a alguien la consagración episcopal sin mandato pontificio, así como el que recibe de él la consagración, incurren en excomunión latae sententiae reservada a la Sede Apostólica". 
Los delitos - las excomuniones como: apostasía, herejía, cisma ${ }^{39}$; el aborto ${ }^{40}$; grabación con cualquier aparato técnico de la confesión verdadera o simulada y de todo lo que habla el confesor o el penitente o la difusión del contenido de la confesión en medios de la comunicación social ${ }^{41}$ - puede absolver el ordinario a sus súbditos y a los que están en el territorio de su jurisdicción o allí cometieron el delito y cada obispo en el acto de confesión sacramental ${ }^{42}$.

\section{La suplencia de la facultad para confesar}

Para administrar válidamente el sacramento de la penitencia se exige, además del orden sacerdotal, que el sacerdote tenga la facultad concedida por una autoridad competente. Pueden darse ciertas situaciones en las que un sacerdote no tiene facultad para administrar el sacramento de la penitencia, pero hay necesidad administrarlo. Cómo proceder en esta situación, para que las confesiones sean válidas y el confesor no incurra en penas canónicas? En determinadas situaciones la Iglesia suple la facultad - „Ecclesia supplet”"43, es decir, concede la facultad que falta, porque sin la facultad la confesión es inválida e ilícita. La Iglesia suple la facultad en caso de error general. El error es un juicio falso sobre una cosa. Es un juicio contrario a la realidad. Pero el error general, o un error colectivo, es el juicio falso (falsa convicción) que tienen todos o la mayoría de los miembros de una colectividad. Se considera que la Iglesia suple la facultad para administrar el sacramento de la penitencia al confesor que antes la obtuvo por un tiempo determinado que ya se venció, pero públicamente se lo desconoce; a los presbíteros que en la parroquia tienen un oficio y por algún motivo desconocido

${ }^{39} \mathrm{CDC}$, can. 1364 § 1: „El apóstata de la fe, el hereje o el cismático incurren en excomunión latae sententiae, quedando firme lo prescrito en el can. $194 \S 1, \mathrm{n} .2$; el clérigo puede ser castigado además con las penas enumeradas en el can. 1336 §1, nn. 2 y 3”. § 2: „Si lo requiere la contumacia prolongada o la gravedad del escándalo, se pueden añadir otras penas, sin exceptuar la expulsión del estado clerical". Cfr. CDC, can. 751.

${ }^{40}$ CDC, can. 1398: „Quien procura el aborto, si éste se produce, incurre en excomunión latae sententiae".

${ }^{41}$ Cfr. Congregación para la Doctrina de la Fe, Decretum de sacramenti Paenitentiae dignitate tuenda, 23 de septiembre 1988, ed: AAS 80 (1988) 1367.

${ }^{42}$ CDC, can. 1355 § 2: „Si no está reservada a la Sede Apostólica, el Ordinario puede remitir una pena latae sententiae, establecida por ley y aún no declarada, a sus súbditos y a quienes se encuentran en su territorio o hubieran delinquido allí; y también cualquier Obispo, pero sólo dentro de la confesión sacramental".

${ }^{43}$ Cfr. CDC, can. $144 \S \S 1-2$; R. Sobański, Władza rzadzenia, en: Komentarz do Kodeksu Prawa Kanonicznego, t. I, ks. I: Normy ogólne, J. Krukowski (dir.), Pallottinum 2003, p. 231-233. 
por los fieles no tienen facultad temporal para administrar el sacramento de la penitencia; a los párrocos y los que por derecho son equiparados a ellos, si no tienen la facultad para confesar por algún motivo desconocido públicamente ${ }^{44}$.

Otra causa de la suplencia de la facultad para confesar es la duda positiva y probable. La duda es el estado de la mente que se queda en suspenso entre la afirmación y la negación respecto al objeto conocido. Existen premisas, para optar a favor de una u otra opción. Resulta difícil decidirse porque no se posee la certeza firme, sino que prevalece la duda. Puede darse duda negativa o positiva. En caso de duda negativa, no existe una razón sensata, o la mente no expresa su juicio sobre el objeto del conocimiento, porque ni objetiva ni subjetivamente tiene razones serias para optar por una de dos afirmaciones opuestas. En caso de duda positiva, los argumentos a favor de las afirmaciones opuestas más o menos se equilibran. En la práctica, es difícil confirmar si las razones subjetivas u objetivas están a favor de la facultad para confesar. Sin embargo, se supone que la duda positiva se da cuando la mente, aunque con razones subjetivas, se inclina por una parte que considera positiva aunque persiste el temor de equivocarse. En la práctica, puede suceder que un sacerdote religioso fue trasladado a una casa religiosa en el territorio de otra diócesis. En el lugar de su anterior domicilio ya perdió la facultad para confesar, porque dejó este lugar de manera definitiva. Para poder confesar en el nuevo lugar (y en cualquier Iglesia) necesariamente debe recibir la facultad del ordinario del lugar de su nuevo destino. El sacerdote religioso, antes de administrar el sacramento de la penitencia en su nuevo destino, tiene que asegurarse, si sus nuevos superiores ya han solicitado para él la facultad para confesar. Si nadie en su comunidad sabe nada sobre este asunto, se le prohíbe confesar. Pero, si alguno de los miembros de la comunidad asegura que posiblemente el superior obtuvo esta facultad para los cohermanos que llegarán a la comunidad, porque se comentó este asunto en alguna oportunidad, pero nadie, hasta ahora, ha visto los decretos que lo afirman, porque el superior no los dejó a nadie y salió de vacaciones, en tal caso, se da la duda positiva. Esto quiere decir que existen premisas positivas de que este sacerdote recibió la facultad para confesar. Sin embargo, no hay posibilidad de averiguarlo en la curia diocesana ni comunicarse con el superior. En tal caso, tiene lugar la duda positiva y el sacerdote puede administrar el sacramento de la reconciliación.

Se han descrito dos situaciones en las que la Iglesia completa la facultad necesaria para la administración valida del sacramento de la reconciliación. Sin embargo, para que suceda esto deben darse ciertas circunstancias. En caso de

\footnotetext{
${ }^{44}$ Cfr. M. Żurowski, Problem władzy i powierzania urzędów w Kościele katolickim, cit., p.
} 176. 
error general, teniendo en cuenta el bien de los fieles, el sacerdote puede confesar en determinadas circunstancias: el penitente se encuentra en una necesidad; existe temor de escándalo si el sacerdote no confesará; hay temor de que el penitente que no ha podido confesarse en este momento tendrá que esperar durante mucho tiempo para tener otra oportunidad; el vicario parroquial puede confesar, si se acordó de que su facultad para confesión ya caducó y hay muchos penitentes cuya confesión resulta una tarea muy difícil para los confesores presentes; el confesor puede acabar las confesiones, si durante la administración del sacramento de la reconciliación se acordó que le caducó su facultad. En las situaciones de duda positiva y probable se puede confesar, si existe causa razonable para administrar este sacramento ${ }^{45}$.

La administración del sacramento de penitencia en situaciones de error general o duda positiva y probable deberían ser fenómenos muy raros. Hay que solicitar lo más pronto posible a la autoridad competente la facultad para confesar.

Vale la pena subrayar que la Iglesia no suple la falta de la fórmula sacramental de la absolución. Excepto en peligro de muerte, cuando no hay tiempo para recitar la fórmula completa (por ejemplo asistiendo a los heridos en un accidente de tránsito), e incluso durante las confesiones de niños, se prohíbe abreviar la fórmula de absolución sacramental ${ }^{46}$.

\section{Las sanciones por confesar sin obtener la facultad}

Hay que recalcar una vez más, que el sacerdote, para administrar válidamente el sacramento de la penitencia, además del poder del orden sagrado, debe tener la facultad. Escuchar la confesión y dar la absolución sacramental sin la facultad está sancionado con la suspensión latae sententiae. ${ }^{47} \mathrm{Si}$ el sacerdote confiesa sin la facultad, puede ser sancionado con otras penas, de acuerdo a la gravedad de

\footnotetext{
${ }^{45}$ Cfr. M. Pastuszko, Sakrament pokuty i pojednania, cit., p. 254.

${ }^{46}$ Cfr. ibidem, p. 260.

${ }^{47} \mathrm{CDC}$, can. 1378 § 1: „El sacerdote que obra contra lo prescrito en el can. 977, incurre en excomunión latae sententiae reservada a la Sede Apostólica”. § 2: „Incurre en pena latae sententiae de entredicho o, si se trata de un clérigo, de suspensión: $1^{\circ}$. quien, sin haber sido promovido al orden sacerdotal, atenta realizar la acción litúrgica del Sacrificio Eucarístico; $2^{\circ}$. quien, fuera del caso de que se trata en el $\S 1$, no pudiendo administrar válidamente la absolución sacramental, trata de darla, u oye una confesión sacramental". Cfr. J. Syryjczyk, Kanoniczne prawo karne. Część szczególna. Warszawa 2003, p. 96-106.
} 
su culpabilidad, no descartando incluso la excomunión ${ }^{48}$. Se incurre en tal pena en el momento de pronunciar las palabras de la absolución sacramental y al hacer los signos prescritos en el ritual, o al comenzar a escuchar la confesión. El delito se comente en el momento de escuchar al menos un pecado confesado por un penitente que piensa que realiza la confesión sacramental. Para incurrir en las penas canónicas, el sacerdote tiene que obrar a sabiendas y de buena voluntad, consciente de que desobedece las normas del Derecho Canónico. De estas penas puede absolver el ordinario (el obispo diocesano o el superior del instituto religioso), y también cada obispo en el acto de la confesión sacramental ${ }^{49}$. Además, si este delito (confesar sin facultad) es secreto, es decir, no puede ser comprobado, y la pena no está declarada, puede absolver de ella, pero solamente en el acto de la confesión sacramental, el canónigo penitenciario ${ }^{50}$, así como el capellán del hospital, de la prisión, durante el viaje marítimo en los lugares de su jurisdicción ${ }^{51}$. Es necesario insistir en que tal pena no se extingue automáticamente, por ejemplo, por la obtención de la facultad para confesar. De las penas canónicas absuelve la autoridad eclesiástica competente, según las normas antes mencionadas.

\section{Conclusión}

Recapitulando el tema, recalcamos una vez más que para la administración válida y lícita del sacramento de la reconciliación de los penitentes con Dios en la Iglesia, además del orden presbiteral, el sacerdote debe tener la facultad. Esta facultad se recibe ipso iure, por oficio, o por concesión del ordinario del lugar que la otorga a los sacerdotes que tienen domicilio en el territorio de su jurisdicción,

${ }^{48} \mathrm{CDC}$, can. 1378 § 3: „En los casos indicados en el §2 pueden añadirse otras penas, según la gravedad del delito, sin excluir la excomunión".

${ }^{49}$ Cfr. CDC, can. 1355 § 2; J. Syryjczyk, Sankcje w Kościele. Część ogólna. Komentarz. Warszawa 2008, p. 298-300.

${ }^{50} \mathrm{CDC}$, can. 508 § 1: „El canónigo penitenciario, tanto de la iglesia catedral como de una colegiata, tiene, en virtud del oficio, la facultad ordinaria, no delegable, de absolver en el fuero sacramental de las censuras latae sententiae no declaradas, ni reservadas a la Santa Sede, incluso respecto de quienes se encuentren en la diócesis sin pertenecer a ella y respecto a los diocesanos, aun fuera del territorio de la misma". Cfr. G. Ciccola, Poradnik spowiednika. Cenzury, nieregularnosci i przeszkody w Kodeksie Prawa Kanonicznego, Kraków 1999, p. 39.

${ }^{51} \mathrm{CDC}$, can. 566 § 2: „En hospitales, cárceles y viajes marítimos el capellán tiene además la facultad, que sólo puede ejercer en esos lugares, para absolver de censuras latae sententiae no reservadas ni declaradas, permaneciendo firme, sin embargo, lo prescrito en el can. 976"; Cfr. G. Ciccola, Poradnik spowiednika, cit., p. 39. 
tanto a diocesanos como a religiosos. Los sacerdotes miembros de institutos religiosos y de sociedades de vida apostólica deben recibir la facultad del propio ordinario para confesar a los propios cohermanos y a los que habitan día y noche en sus mismas casas. Se debe tener muy en cuenta la importancia, la validez y la licitud del sacramento de la penitencia, ya que la Iglesia pone estas exigencias, incluso sancionando con la pena de suspensión latae sententiae por desobedecer estas normas que siempre velan por el bien del presbítero y del penitente.

\section{Bibliography}

Adamowicz L., Zakres uprawnień spowiednika według prawa powszechnego Kościoła tacińskiego i prawa wspólnego katolickich Kościołów wschodnich, Lublin 2001.

Ciccola G., Poradnik spowiednika. Cenzury, nieregularnosci i przeszkody w Kodeksie Prawa Kanonicznego, Kraków 1999.

Código de Derecho Canónico del año 1917.

Código de Derecho Canónico del año 1983.

Congregación para la Doctrina de la Fe, Decretum de sacramenti Paenitentiae dignitate tuenda, 23 de septiembre 1988, ed: AAS 80 (1988) 1367.

Gajda P.M., Sankcje karne w kościele wświetle kodeksu Prawa Kanonicznego Jana Pawła II oraz późniejszych uzupetnień. Studium kanoniczno-pastoralne, Tarnów 2008.

Gambari E., Życie zakonne po Soborze Watykańskim II, Kraków 1998.

Górka M., La natura di potestas absolvendi a peccatis, Roma 1992.

Krukowski J., Sakrament pokuty, en: Komentarz do Kodeksu Prawa Kanonicznego, t. III/2, ks. IV: Uświęcające zadanie Kościoła, J. Krukowski (dir.), Pallottinum 2011, s. $140-181$.

Pastuszko M., Sakrament pokuty i pojednania, Kielce 1999.

Płatek J.S., Sprawowanie sakramentu pokuty i pojednania, Częstochowa 2001.

Syryjczyk J., Kanoniczne prawo karne. Część szczególna, Warszawa 2003.

Syryjczyk J., Sankcje w Kościele. Część ogólna. Komentarz, Warszawa 2008.

Sobański R., Władza rzadzenia, en: Komentarz do Kodeksu Prawa Kanonicznego, t. I, ks. I: Normy ogólne, J. Krukowski (dir.), Pallottinum 2003, s. 212-233.

Żurowski M., Problem władzy i powierzania urzędów w Kościele katolickim, Kraków 1985. 
